Supplement of E\&G Quaternary Sci. J., 68, 53-73, 2019

https://doi.org/10.5194/egqsj-68-53-2019-supplement

(C) Author(s) 2019. This work is distributed under

the Creative Commons Attribution 4.0 License.

(c) (1)

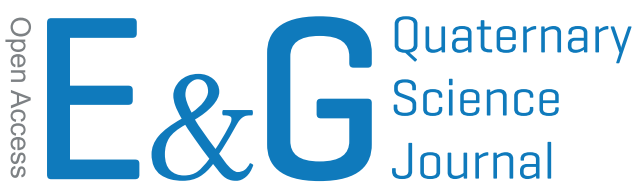

Supplement of

\title{
New chronological constraints on the timing of Late Pleistocene glacier advances in northern Switzerland
}

Dorian Gaar et al.

Correspondence to: Frank Preusser (frank.preusser@geologie.uni-freiburg.de)

The copyright of individual parts of the supplement might differ from the CC BY 4.0 License. 


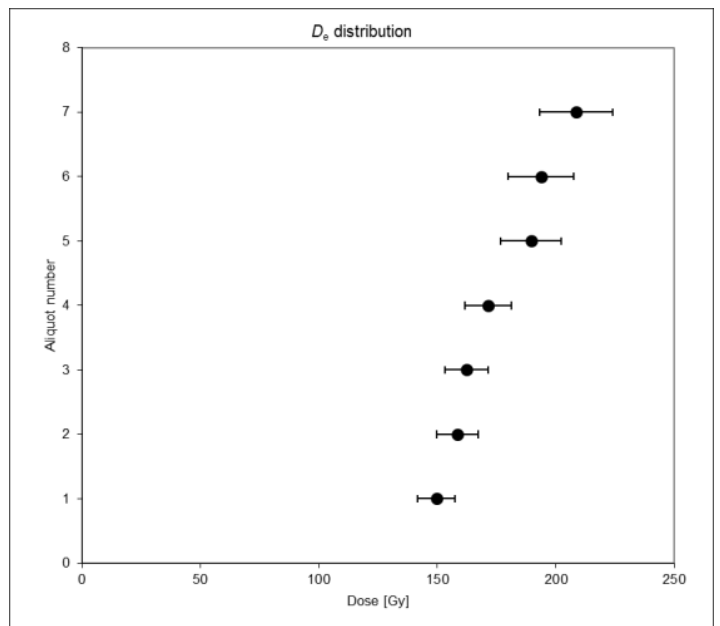

BIR-1 poly IR50 (fine grains)

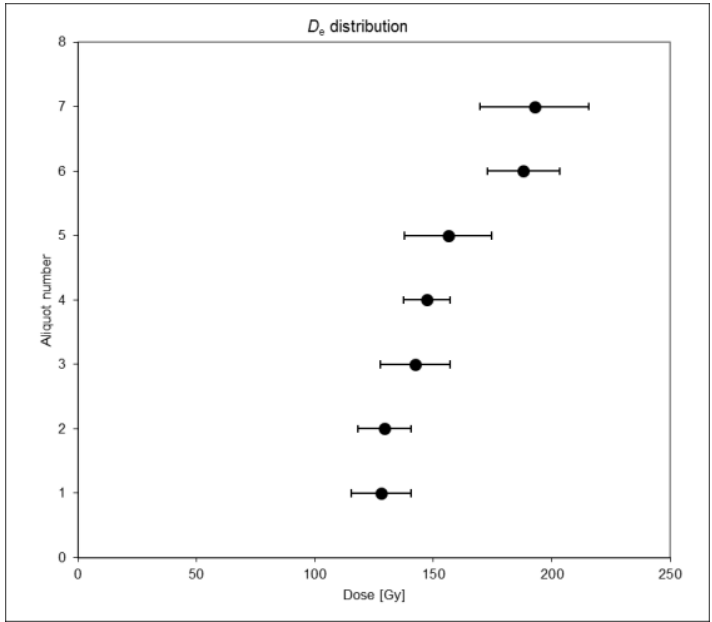

BIR-1 quartz OSL (fine grains)

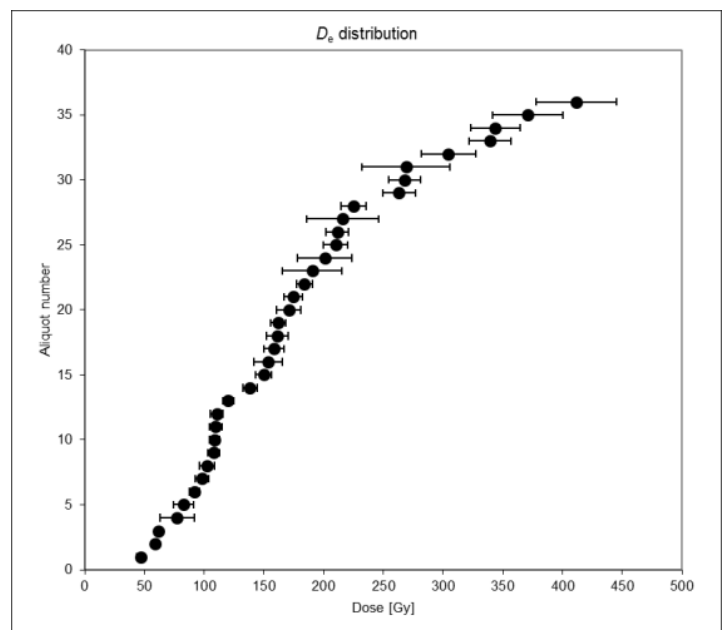

BIR-2 feldspar IR50 (1 mm aliquots)

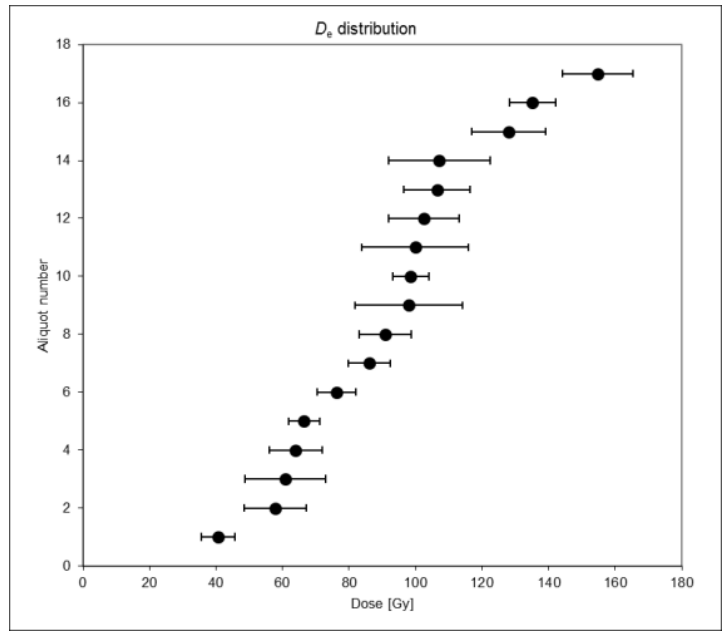

BIR-2 quartz OSL (2 mm aliquots)

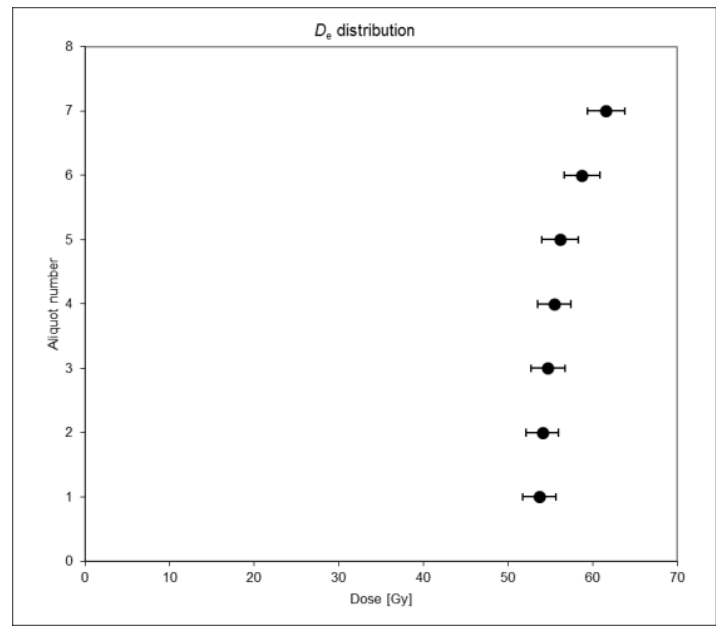

BIR-3 poly IR50 (fine grains)

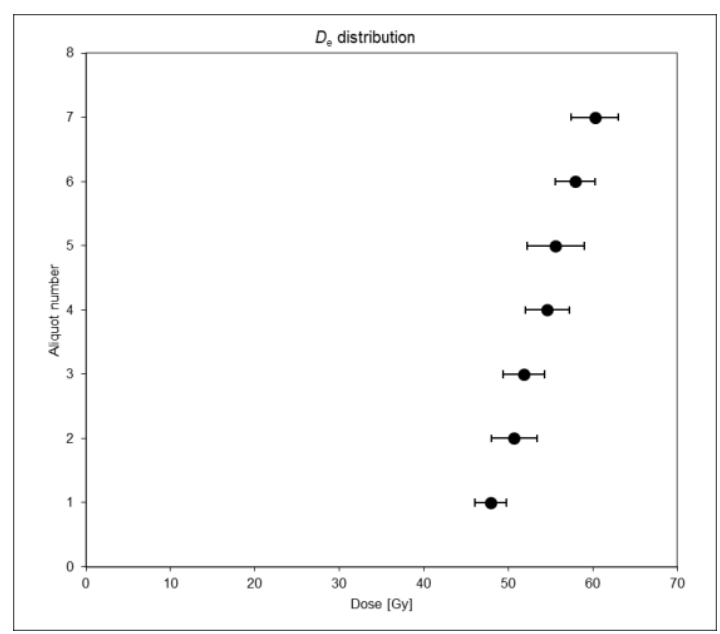

BIR-3 quartz OSL (fine grains) 


$$
\frac{f}{I} \frac{f}{I}
$$




$$
\frac{f}{f} \frac{f}{L}
$$




$$
\frac{f}{r} \frac{i}{r}
$$

